\title{
VELDEN, Felipe Ferreira Vander. 2018. Joias da floresta: antropologia do tráfico de animais. São Carlos: EdUFSCar, 279pp.
}

Jỗo FRANCISCO KLEBA LISBOA

O exemplo escolhido por Felipe Ferreira Vander Velden para dar início à Introdução de seu livro não poderia ser melhor: narrar o fulminante desaparecimento da ararinha-azul-de-Spix, ou ararinha-azul, de seu hábitat natural no sertão da Caatinga, às margens do rio São Francisco, entre Bahia e Pernambuco. Nesse curso, o leitor vai sendo apresentado ao que aparenta ser o propósito profundo de "Joias da floresta”, não apenas uma antropologia do tráfico de animais, como indica o subtítulo, mas algo muito mais grave, mortal e inquietante: uma antropologia da extinção. Familiarizar o leitor desavisado (ou dialogar com especialistas nessa área que, enfim, vem ganhando a devida atenção, sobretudo em torno da noção de Antropoceno) com termos como "a sexta onda de extinções", "tanatosfera”, "zona de morte" e "força assassina", portanto, é a tarefa primária assumida logo de início. E o contraste dessa história trágica e total com a mistura de fragilidade, raridade e beleza singular que é a ararinha-azul faz potencializar a intenção do autor.

O objeto de "Joias da floresta" é bem definido: abordar as redes, fluxos e movimentos de circulação de animais silvestres - ou de partes de seus corpos, como será importante ressaltar - em seus múltiplos níveis (locais, nacionais, transnacionais) e atores (humanos, como caçadores, atravessadores e colecionadores, ou não humanos, como pássaros, insetos, buritizais, igarapés), que conectam os diversos ecossistemas do mundo aos compradores de tais “mercadorias", transportando-as sobretudo aos países desenvolvidos do norte. Mais especificamente, a pesquisa que dá base ao livro é focada em uma microparcela dessa rede, localizada na região norte do estado de Rondônia, onde vivem os Karitiana, povo indígena que ora ocupa a posição de fornecedores, e suas conexões com compradores das cidades e povoados vizinhos, sobretudo a capital do estado, Porto Velho. 
O tratamento desse fenômeno sob seu aspecto jurídico, ou seja, como crime de tráfico de animais, é acionado ao longo do livro de forma estratégica e intermitente, assim como o viés preservacionista e ambiental, que se junta ao legal, para levar à frente o combate a tal prática. Pois Velden está lidando com o terceiro maior tipo de tráfico ilícito em valor movimentado no mundo: perde apenas para o de drogas e o de armas, e estima-se que, só o Brasil, de onde entre 12 milhões e 38 milhões de animais são retirados anualmente da natureza, movimente algo em torno de U\$ 1 bilhão. Ao mesmo tempo, o caráter fluido, movediço e errante dos animais, assim como de plantas e microrganismos, desafia constantemente as divisões, barreiras, fronteiras e delimitações, sejam elas físicas, políticas ou epistêmicas. Dentre as classificações semânticas melhor exploradas por Velden encontra-se a que separa domesticidade de selvageria - juntamente com os questionamentos e inadequações a ela associados -, onipresente e problemática a ponto de ser um dos fios condutores do livro. Outra divisão estruturante está contida na própria definição dupla do que seja tráfico, ora se referindo a comércio ou trato mercantil em geral, ora à atividade ilícita e ao negócio clandestino. É na passagem de um sentido ao outro que reside o olhar de Velden (e o de alguns de seus interlocutores) sobre o tema.

"Jóias da Floresta" é fruto de uma pesquisa de pós-doutorado de 24 meses, incluindo um estágio de 7 meses na Aarhus Universitet, na Dinamarca. O livro é dividido em duas partes. Na primeira, trata-se de abordar o movimento de animais, sobretudo enquanto mercadorias, pelo mundo (cap. 1) e aos poucos vai-se afunilando o escopo para o tráfico de animais, até chegar em Rondônia e sua capital, Porto Velho. O combate ao tráfico de animais silvestres no mundo e no Brasil é objeto de uma rápida revisão histórica nos dois capítulos seguintes, que abordam a formação conjunta de novas sensibilidades e de novas instituições e mecanismos legais, sobretudo a partir da década de 1960, seja nos Estados Unidos ou no Brasil, ou ainda com a $1^{\text {a }}$ Conferência das Nações Unidas para o Meio Ambiente Humano, realizada em 1972, em Estocolmo. Destaque merecido é dado ao ato seguinte à Conferência: a CITES (Convenção sobre o Comércio Internacional de Espécies da Fauna e Flora Selvagens em Perigo de Extinção), de 1973, firmada em Washington, EUA, considerada ainda hoje a "Magna Carta" no assunto, e da qual o Brasil é signatário desde 1975.

Apesar das massivas quantidades de produtos selvagens de origem animal exportadas desde a conquista, é no século XX que se consolida um mercado de peles e couros de luxo, além de plumas e outros adereços que compunham as "fantasias" utilizadas pela indústria da moda e do cinema, com fartos exemplos destacados pelo autor. Manaus foi sem dúvida o epicentro dessa produção, verdadeira drenagem amazônica para os países abastados (Europa, Estados Unidos, Canadá, Japão, Argentina), até a lei de 1967 proibir a prática e a transferir para o mercado ilícito do tráfico. Hoje as aves ocupam a dianteira do comércio ilegal, no qual o Brasil é um dos grandes fornecedores de psitacídeos (araras, periquitos, papagaios etc), seguidas pelos répteis (que além dos couros e peles, compõem o mercado crescente de pets exóticos, como iguanas, cobras e quelônios) e pelos mamíferos (o Brasil, novamente, abrigando 95\% das espécies mais traficadas de primatas, inclusive para laboratórios da indústria farmacêutica), com suas vultuosas peles e alimentando os mais diversos fetiches, experiências gustativas e mesmo a medicina tradicional chinesa. 
Os dados trazidos por Vander Velden, nesse aspecto, são fartos, precisos e finamente descritos. Em vez de apresentá-los na forma de um relatório exaustivo, como o desfile de números intermináveis, opta por um estilo capaz de produzir sensações e imagens que tornam a leitura do livro prazerosa e instigante. Velden conduz o leitor em meio a inúmeras espécies e países tropicais, florestas e savanas, ambientes gelados, aves e insetos coloridos, répteis sorrateiros, seres minúsculos e inofensivos, predadores e grandes mamíferos. Ao mesmo tempo, percorre os meandros desse mercado global, chegando aos salóes de troféus dos caçadores, às grifes europeias, aos viveiros de pássaros indonésios e aos zoológicos, coleções, circos e lares norte-americanos (país que consome cerca de $20 \%$ dos animais traficados). Isso sem perder o foco da dimensão do problema em termos quantitativos e absolutos, o que tem por efeito causar uma poderosa impressão do tamanho do impacto produzido no reino animal por esse circuito insaciável de transformação da vida em mercadoria.

No cap. 4 chega-se a Rondônia, que apesar de tudo não figura entre as principais regiões do país em captura de animais silvestres, e relatos indicam que ali a atividade está em forte declínio - a opção pelo local, portanto, deve-se mais à entrada prévia do autor nesse campo (desenvolve pesquisa com os Karitiana desde 2003, sendo que seu doutorado, em 2010, abordou a relação destes com animais de criação, ou domésticos) do que à sua associação direta com o tema. O destaque em Porto Velho vai para os passarinheiros, que capturam sobretudo curiós, famosos pelas disputas de canto, que abastecem o mercado local e integram uma rede amazônica de circulação desses pássaros. A primeira parte ainda conta com outros dois capítulos, que abordam de perto as pessoas que compram e mantêm animais silvestres. A ideia é suprir o que o autor chama de desinteresse antropológico pela domesticidade e pelo cotidiano, dado que tais relações envolvem grande carga afetiva e de valores, remetendo também ao tratamento do problema enquanto "questão cultural" de certas áreas ou populações do país. O caso do macaco Chico, em São Carlos, no interior paulista (lembrando que Velden é professor na UFSCar), que ilustra o cap. 6, serve de exemplo dessa relação que chega ao limite do familiar (o episódio causou comoção e intenso apelo midiático quando Chico foi retirado dos braços de sua dona pela polícia, após 37 anos de convívio. Uma decisão judicial restituiu Chico à família, mas o macaco morreu pouco depois, fazendo sua dona exclamar: "perdi um filho").

A segunda parte do livro, "Dos delitos das penas", tem sete capítulos e foca nos Karitiana, povo de língua Tupi, com aproximadamente 314 indivíduos, em que os homens adultos são prioritariamente caçadores (atualmente usam arma de fogo) e têm preferência pela carne de macaco, mas também abatem porcos do mato, cutias, veados, antas e alguns pássaros. Pesca e horticultura também compóem sua base alimentar. Seu território tradicional foi atingido pela expansão da sociedade brasileira no início do século XX, e o contato se tornou mais intenso nos anos 1940, por conta da ação dos "soldados da borracha", tendo os Karitiana sido assentados pelo órgão indigenista nos anos 1960. A Terra Indígena Karitiana, com quase 90 mil hectares, situa-se integralmente no município de Porto Velho, e ainda é farta em caça em alguns pontos, embora os Karitiana venham reclamando de escassez e diminuição dos animais de presa (caça e pesca), por conta de sua perda de mobilidade e da pressão externa sobre a Terra Indígena. Dentre as fontes alternativas de geração de renda, sobressai-se a confecção e comercialização de artesanatos com penas e outras partes que "sobram" após o consumo da carne do animal. Esse trecho 
do livro trás também algumas figuras, sobretudo fotos do artesanato indígena feito com penas e dentes, tiradas pelo autor ou retiradas da internet.

Para muitos povos caçadores, como os Karitiana, as partes dos animais caçados que não são consumidas na alimentação, como os ossos, pele e garras, devem receber um destino adequado e seguro, a salvo de bichos, sangue ou excrementos, e não podem ser simplesmente descartadas. Caso contrário, o caçador pode sofrer grave consequência e ficar panema, tornando-se imprestável para caça. Eis que o artesanato se apresenta como uma ótima saída para dar um destino correto a tais restos, além de trazer renda extra para os caçadores e suas famílias. Um dos pontos fortes do livro é o tratamento dado a esse fenômeno recente e sua relação com a cosmologia indígena, para a qual os animais são sujeitos, ou pessoas, ou seja, criaturas com corpo, alma e roupa - se pensarmos que garras, dentes e espinhos são vistos como "artefatos culturais" dessa "gente", com suas respectivas potencialidades agentivas. Tais criaturas, portanto, devem passar necessariamente por um processo de objetificação, sendo despidas de seus atributos e capacidades (equivalentes à sua humanidade), antes de serem consumidas.

A arte plumária dos Karitiana, também definida como artesanato indígena (termo incluído na CPI da biopirataria, encerrada em 2006), passa a ser o principal alvo da investigação. Aqui entra em cena o dilema entre as chamadas práticas tradicionais, ou necessidades culturais, e o que se entende pelos direitos dos animais à vida e sua proteção contra os maus-tratos. A lei de crimes ambientais (Lei 9.605), em vigor desde 1998, é acionada pela Polícia Federal para coibir o comércio de artesanato (brincos, colares, prendedores de cabelo) entre os Karitiana. O papel do Estado é abordado com mais ênfase nos últimos capítulos do livro, assim como as contradições inerentes a ele. Dentre estas, o choque provocado entre o enquadramento do artesanato indígena como crime ambiental e a visão idílica, romântica, nacionalista, dos indígenas enquanto guardiões (naturais?) da natureza; ou a oposição simplista entre "matar para comer" e "matar para vender" levantada por alguns ambientalistas, carregada de forte conteúdo moral e desconfiança sobre a suposta ganância e dissimulação de alguns indígenas.

Um dos pontos de interrogação ao longo da leitura do livro recai sobre a expressão - amplamente usada por Velden e um dos eixos centrais de sua argumentação - "animais vivos, seus corpos, ou suas partes". O incômodo talvez se deva ao intuito de abarcar em uma mesma categoria, considerando um mesmo fenômeno social, coisas bem diferentes, como o tráfico de animais belos e raros, mas sobretudo vivos, para colecionadores; a venda de carne e subprodutos animais com diversas aplicações industriais (medicinais, cosméticas, vestuais etc.); a venda de artesanato indígena como fonte de renda alternativa e destinação adequada aos "restos" da caça. Mesmo que a oposição entre animais vivos e suas partes/ artefatos seja questionada do ponto de vista etnológico - uma vez que muitos objetos que consideramos inertes são, para os indígenas, dotados de múltiplas agencialidade - o leitor não sai inteiramente convencido dessa opção, generalizante ao extremo. Parece que se está lidando com algo mais próximo à generalização feita pelo Estado, ao considerar crime igualmente comercializar "espécimes da fauna silvestre" ou "produtos e objetos dela oriundos". Tal postura legal ajuda a manter a atuação dos agentes do Estado fria e impessoal (objetificante?), distante o suficiente tanto dos humanos quanto dos animais envolvidos nessas relações mercantis. Para os propósitos da antropologia, no entanto, e certamente para os sujeitos/atores envolvidos nessas tramas, não se trata da mesma coisa. 
O escopo global proposto pelo autor também se manifesta no projeto de realizar uma antropologia do tráfico de animais (Parte I), em que pese sua etnografia ter se dedicado aos conflitos conceituais, antropológicos e jurídicos em torno da problemática noção de artesanato indígena (Parte II). Também aí reside uma sensação de lapso empírico/conceitual, em que coisas diferentes são tratadas como se fossem a mesma. De resto, o livro tem muitas qualidades e é elogiável por vários motivos, dentre os quais destaca-se tratar com a devida seriedade e minúcia um tema urgente, vital e universal, ao mesmo tempo que aborda sua dimensão familiar, doméstica e afetiva. Transita entre o global e o local, denunciando a sanha capitalista em transformar em mercadoria todas as formas de vida, mas jogando luz nas resistências, mesmo que em escala microscópica, dessa vida em se deixar capturar.

João Francisco Kleba Lisboa é doutor em Antropologia pelo PPGAS/UnB e professor substituto do Departamento de Antropologia da UFPR.

RECEBIDO: $09 / 08 / 2019$

APROVADO: $15 / 08 / 2019$ 